
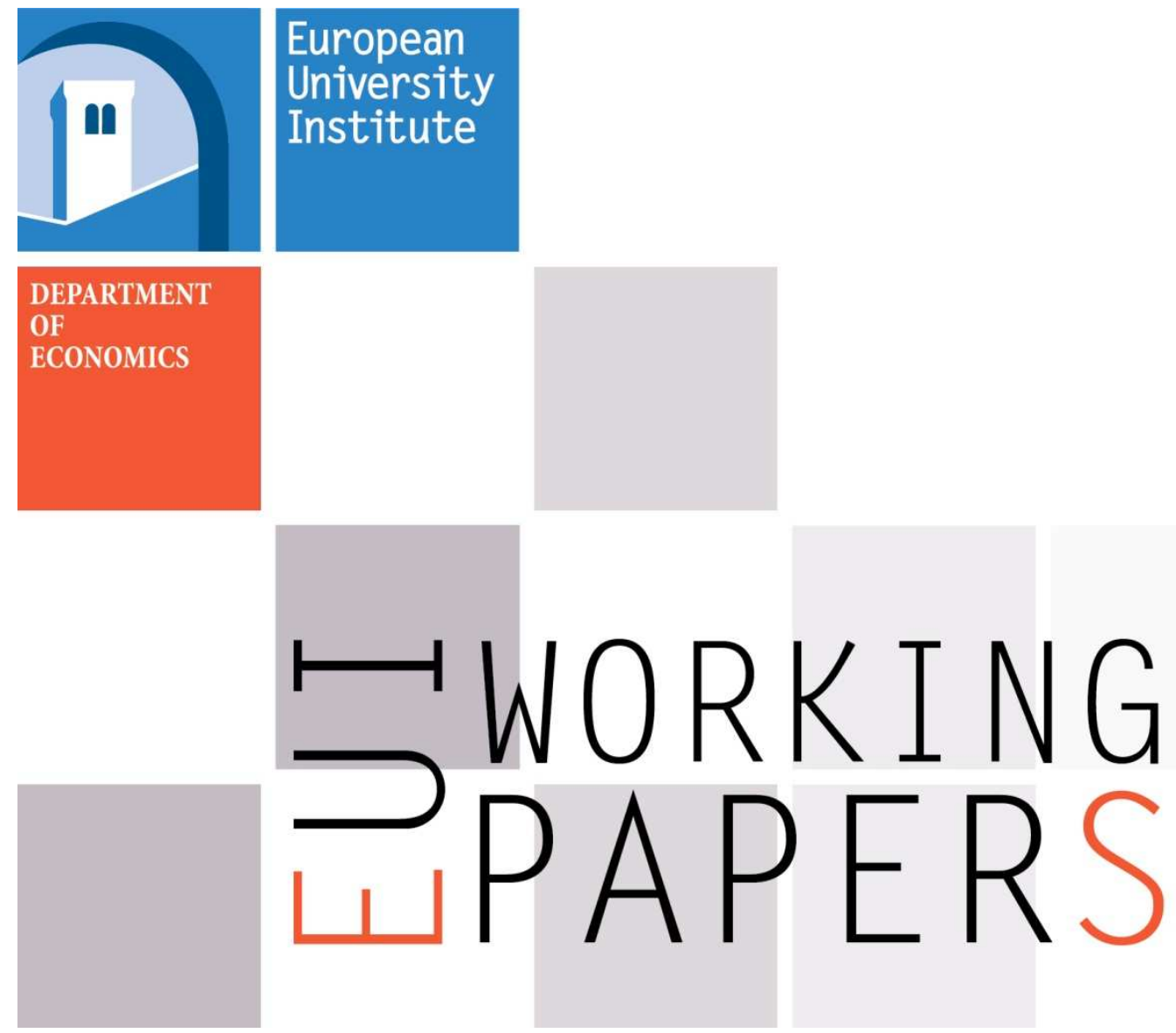

ECO 2014/01

Department of Economics

THE HIDDEN COSTS OF TAX EVASION:

COLLABORATIVE TAX EVASION IN MARKETS FOR EXPERT SERVICES

Loukas Balafoutas, Adrian Beck, Rudolf Kerschbamer and Matthias Sutter 

European University Institute

Department of Economics

The Hidden Costs of Tax Evasion: Collaborative Tax Evasion in Markets for Expert Services

Loukas Balafoutas, Adrian Beck, Rudolf Kerschbamer and Matthias Sutter

EUI Working Paper ECO 2014/01 
This text may be downloaded for personal research purposes only. Any additional reproduction for other purposes, whether in hard copy or electronically, requires the consent of the author(s), editor(s). If cited or quoted, reference should be made to the full name of the author(s), editor(s), the title, the working paper or other series, the year, and the publisher.

ISSN 1725-6704

(C) Loukas Balafouas, Adrian Beck, Rudolf Kerschbamer and Matthias Sutter, 2014

Printed in Italy

European University Institute

Badia Fiesolana

I - 50014 San Domenico di Fiesole (FI)

Italy

www.eui.eu

cadmus.eui.eu 



\title{
The Hidden Costs of Tax Evasion
}

\section{Collaborative Tax Evasion in Markets for Expert Services}

\author{
Loukas Balafoutas $^{\mathrm{a}}$ \\ Adrian Beck ${ }^{\mathrm{b}}$ \\ Rudolf Kerschbamer ${ }^{\mathrm{c}, *}$ \\ Matthias Sutter ${ }^{\mathrm{d}}$ \\ ${ }^{a}$ Department of Public Finance, University of Innsbruck. Email: loukas.balafoutas@uibk.ac.at

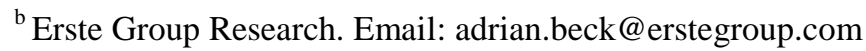 \\ ${ }^{c}$ Department of Economics, University of Innsbruck. Email: rudolf.kerschbamer@uibk.ac.at \\ ${ }^{\mathrm{d}}$ Department of Economics, European University Institute Florence and \\ Department of Economics, University of Cologne. Email: matthias.sutter@eui.eu
}

\begin{abstract}
In markets where transactions are governed by contractual incompleteness, revealed intentions to evade taxes may affect market performance. We experimentally examine the impact of tax evasion attempts on the performance of credence goods markets, where contractual incompleteness results from asymmetric information on the welfare maximizing quality of the good. We find that tax evasion attempts - independently of whether they are successful or not - lead to efficiency losses in the form of too low quality and less frequent trade. Thus, shadow economies induce an excess burden not only by hampering the collection of tax revenues, but also by reducing market efficiency.
\end{abstract}

JEL Classification: C72, C91, D82, H26

Keywords: Credence Goods, Expert Services, Tax Evasion, Fraud, Experiment

This version: 24. January 2014

*Corresponding author: Department of Economics, University of Innsbruck, Universitätsstrasse 15, A-6020

Innsbruck; Email: Rudolf.Kerschbamer@uibk.ac.at; Phone: +43 5125077300 


\section{INTRODUCTION}

Each year trillions of dollars slip through the tax authorities' fingers as a consequence of tax evasion. In the United States, for example, the overall net tax gap in 2001 was estimated to be approximately $\$ 290$ billion. $^{1}$ A substantial body of theoretical and empirical work addresses the problem, focusing mainly on the effects of institutional remedies against tax evasion. ${ }^{2}$ While the research focusing on variables that are capable of influencing the amount of evaded taxes is vital and indispensable, some of the welfare consequences of tax evasion are often ignored. Considering the government as a provider of public goods and services financed by tax revenues, tax evasion is detrimental for the simple reason that it increases the excess burden of collecting a given tax revenue by increasing the tax rate and thereby the distorting effect of the tax (Feldstein, 1999). Additionally, a negative impact on welfare can emerge due to efforts made when taxpayers try to conceal and tax authorities try to detect tax evasion (see, e.g., Bayer, 2006), due to the uncertainty tax evasion imposes on risk-averse evaders (Yitzhaki, 1987) and due to distortions in competition arising when tax-evading firms drive tax-honest ones out of the market (as in Strand, 2005, for instance). In this paper we argue that in markets where transactions are governed by contractual incompleteness an additional welfare impact of attempted and successful tax evasion might result from its effect on agents' incentives of exploiting their informational advantage to their benefit and to the detriment of their trading partners and of overall efficiency.

Key to our argument is the observation that in many markets the approval of both trading partners is needed to evade taxes. This cooperative dimension of tax evasion implies that at some point the trading partners have to reveal their preferences regarding tax evasion to each other. ${ }^{3}$ In markets governed by incomplete contracts it seems plausible that the revelation of an agent's attitude regarding tax evasion influences the trading partner's

\footnotetext{
${ }^{1}$ This gap is composed of not fully reporting taxable income, not timely paying the full amount of tax reported, or not filing required returns on time (U.S. Department of the Treasury, IRS, 2005 and 2006). For a classification and estimation of the extent of the total shadow economy, of which tax evasion constitutes a substantial part, see Schneider and Enste (2000).

${ }^{2}$ The seminal work by Allingham and Sandmo (1972) models citizens' decisions about which fraction of income to declare as a simple portfolio decision problem and determines the effects of changes in exogenous factors such as tax and penalty rates and the probability of detection. Later work, e.g., by Yitzhaki (1979), Reinganum and Wilde (1985), and Alm, McClelland, and Schulze (1992) refines the analysis of optimal taxation, again mainly focusing on the effects of changes in the institutional framework in which tax evasion potentially occurs. The theoretical work is accompanied by empirical studies analyzing field data (see, e.g. Clotfelder, 1983, Feinstein, 1991, and Slemrod, 2007) as well as by laboratory and field experiments (e.g. Baldry, 1986, 1987, Torgler, 2002, 2004, Kleven et al., 2011). For surveys of the literature on - and the economics of - tax evasion see Andreoni, Erard, and Feinstein (1998) and Slemrod (2007).

${ }^{3}$ Literature on this cooperative dimension of tax evasion is scarce. Notable exceptions are Boadway et al. (2002) and Chang and Lai (2004), who present theoretical models in which tax evasion requires collusion among tax evaders, mainly focusing on the effects of exogenous sanctions on (collaborative) tax evasion.
} 
sentiments towards the agent and therewith the behavior in the underlying market. In this paper we will experimentally investigate the impact of revealed intentions regarding tax evasion on the performance of a market characterized by incomplete contracts - a topic that has to the best of our knowledge not yet been explored in the literature

The setting in our controlled laboratory experiment is a market for expert services often also referred to as a credence goods market (see Dulleck and Kerschbamer, 2006, for a general framework and an overview of the theoretical literature). Such markets are plagued by serious contractual incompleteness due to superior information of the seller on the quality that yields the highest surplus from trade. Common examples are health services, where the doctor knows better than the patient which disease the latter has and which treatment is appropriate; all kinds of repair services, where the expert knows more about the type of service the item needs than the owner; and taxicab rides in an unknown city, where the driver is better informed about the shortest route to the destination than the tourist. On top of the asymmetric information on the welfare maximizing quality, in many markets for expert services there is also asymmetric information on the quality provided. For instance, in the market for medical services a patient might be unable to tell ex post whether the injection he received contained a high-cost substance or not.

The informational asymmetries present on credence goods markets imply that complete contracts are infeasible. This opens the door to a whole array of different types of fraudulent behavior on the sellers' side, including overtreatment (providing a higher quality than the surplus maximizing one), undertreatment (choosing a quality that is insufficient to satisfy the consumer's needs), and overcharging (charging for a higher quality than has been provided). Furthermore, anticipated fraud might lead consumers to abstain from the market altogether, leading to further efficiency losses. ${ }^{4}$ Our main hypothesis is that the size of the efficiency losses resulting from contractual incompleteness depends on the trading partners' revealed intentions to evade taxes. Specifically, we expect that different constellations of revealed intentions to evade taxes in a stage in which tax evasion can be agreed on have

\footnotetext{
4 Although standard theory assuming own-money-maximizing and risk-neutral preferences predicts low efficiency on markets governed by incomplete contracts, recent experimental studies - by Dulleck et al. (2011) and Beck et al. (2013) for markets for credence goods and by Huck et al. (2010, 2012, 2013) for markets for experience goods - have shown that such markets work considerably better than predicted, probably due to agents' social preferences.
} 
different implications for the subsequent behavior of agents trading on the market and thus for the efficiency of transactions. ${ }^{5}$

As an example of a credence goods market in which, at least judged by the vast anecdotal evidence (see, e.g., OECD, 2004) joint tax evasion is widespread, consider the market for car repair services. Here - as in many other markets - a conducted transaction can either be reported or not reported to tax authorities. That is, before actual trade takes place a car mechanic and a consumer can agree on evading the value added tax by concealing the sale and they can then split the associated gains. This way, tax evasion is ceteris paribus profitable for both parties as long as it is not detected. However, the efficiency of the subsequent market transaction may be affected by the revealed intention to evade or to pay the transaction tax.

On the one hand, a mutual agreement to pay or to evade taxes can decrease the social distance between the trading parties. Reduced social distance has been demonstrated to lead to more cooperative behavior, for instance by Charness et al. (2007) and by Götte et al. (2012). Based on this evidence we would expect that agents behave nicer towards trading partners who reveal the same attitude regarding tax evasion. In the case where a mutual agreement to pay taxes leads to nicer (i.e., more trustful or more trustworthy) behavior we refer to this as the solidarity effect, while in the case where a mutual agreement to evade taxes leads to nicer behavior we will refer to a conspiracy effect.

On the other hand, in constellations where one trading partner reveals the intention to pay while the other reveals the intention to evade taxes each player might have negative emotions against the other, leading them to exhibit less trustful and trustworthy behavior, thereby decreasing the efficiency of a transaction. We call this the punishment effect. Systematic differences in the market behavior of sellers in different constellations of revealed intentions to evade taxes might also arise if the revealed intentions to evade taxes are driven by preferences which also drive market behavior. For instance, it seems plausible that more pro-social sellers are not only less inclined to evade taxes but also less willing to defraud

\footnotetext{
${ }^{5}$ While parts of the literature on tax evasion already incorporate non-standard preferences into their models, the focus is typically on the impact of such preferences on the evasion decision. For instance, Spicer and Becker (1980) study the impact of fairness perceptions on this decision, Gordon (1989) introduces a psychological cost of evasion, Erard and Feinstein (1994) adapt the concepts of guilt and shame to the context of tax compliance, Frey and Torgler (2007) study the impact of perceptions regarding the compliance of other taxpayers on evasion, and Konrad and Quari (2012) study the effect of patriotism on compliance. By contrast, our focus is not on the compliance decision per se but rather on the question whether different outcomes on the compliance stage have different implications for the subsequent behavior of agents trading on the market and thus for the efficiency of that market.
} 
consumers. ${ }^{6}$ We call this the selection effect. Finally, differences in the trading partners' behavior under different constellations of revealed intentions might also result when taxes are actually evaded in one, but paid in another constellation. We call this the cake size effect. In addition to these direct effects an impact on efficiency might also arise if sellers who reveal their willingness to pay or to evade taxes are expected to be more or less likely to defraud their consumers (because of the solidarity, the conspiracy, the punishment, the selection or the cake size effect). Consumers may then be more or less willing to interact, producing a further impact on efficiency. Given all those effects it is not a priori clear whether attempted or actual tax evasion has a positive, negative, or no impact on the efficiency of the underlying market.

Returning to our example, a customer in a garage would have to consider not only the financial benefits and risks of tax evasion, but she also has to take into account that the quality of the service provided by the mechanic could be different than what she would have gotten if she had decided to pay the tax. In the same spirit, the car mechanic should take into account that revealing his willingness to evade taxes might scare the consumer away. ${ }^{7}$

Our results show that revealed intentions to evade taxes lead to efficiency losses independently of whether taxes are actually evaded or not. The drop in efficiency is driven by large differences in interaction and undertreatment rates. In particular, tax-honest consumers are much less likely to enter the credence goods market if they know they will have to interact with a tax-dishonest seller. Also, if a transaction takes place, the undertreatment rate is higher when at least one of the agents has revealed the intention to evade taxes than in constellations where both transaction partners are tax honest. Using control treatments to disentangle the various effects of revealed intentions regarding tax compliance, we find evidence for the existence of the solidarity effect between two tax-honest agents and the conspiracy effect between two tax-dishonest agents, both leading to less fraud when agents reveal the same tax attitude. We also find some evidence for the existence of a selection effect, with tax-dishonest sellers being more likely to defraud their customers, but no evidence for the existence of a punishment effect or a cake size effect. Overall, our results suggest that tax evasion reduces welfare not only by increasing the excess burden of collecting a given tax revenue, by inducing agents to incur costs to hide or to uncover taxable transactions, by distorting

\footnotetext{
${ }^{6}$ The literature in the previous footnote argues that the reasons for tax compliance go far beyond simple considerations of monetary risk.

${ }^{7}$ Note that in real markets differences in behavior between the taxed and the untaxed sector might also arise from differences in institutional consumer protection. For instance, liability rules might only apply in the taxed but not in the untaxed sector. We abstract from such differences to isolate the sheer effect of collaborative tax evasion on the performance of the market on which the transaction takes place.
} 
competition between tax-honest and tax-evading firms and by imposing risk on tax evaders, but also by creating an additional ('hidden') efficiency loss on the underlying market.

\section{A CREDENCE GOODS GAME}

\subsection{Basic framework}

We base our experimental investigation on a simplified version of a model on expert services by Dulleck and Kerschbamer (2006). In this two-player sequential-move game, a consumer $(c$; she) has a problem $\theta$ which is either major and requires a high-quality service, or minor and requires a low-quality service. While the consumer herself only knows the ex ante probability $h(1-h)$ of having the major (minor) problem, an expert seller $(s$; he) receives full information about the type of the consumer's problem. More specifically, the sequence of the game is as follows: After observing exogenously given prices $p^{l}$ (representing the price of a low-quality service) and $p^{h}$ (representing the price of a high-quality service), with $p^{l}<p^{h}$, the consumer decides whether to buy a service from the expert seller or to opt out of the market. In the former case, a random move by nature $(n)$ determines the consumer's problem; the seller learns the realization of this random move (by performing a free diagnosis) and then provides a service of either low $(l)$ or high $(h)$ quality. We denote the index of the quality provided by $\tau \in\{l, h\}$. The high quality service $(\tau=h)$ solves both types of problems, while the low quality service $(\tau=l)$ is only sufficient for minor problems. Let $c^{\tau}$ denote the costs of quality $\tau$, and $c^{l}<c^{h}$. For the quality he claims to have provided the expert can then charge the associated price (either $p^{l}$ or $p^{h}$ ). We denote the index of the quality charged for by $\imath \in\{l, h\}$.

The material payoffs in case of an interaction are such that the seller obtains the price he charged from the consumer and has to bear the costs for the quality provided, i.e., in the baseline game the seller's profit is $\pi_{s}^{b}=p^{l}-c^{\tau}$. For future reference we define a situation in which the expert provides the low-quality service and charges for the high-quality service as overcharging; and we refer to a situation in which the expert provides the low quality to a consumer who has the major problem as undertreatment. ${ }^{8}$ The consumer's payoff in case of an interaction depends on whether the provided service solved her problem: she receives the value $V$ if the quality was sufficient $(\tau \in\{l, h\}$ if $\theta=l$; and $\tau=h$ if $\theta=h$ ) and zero otherwise; and she has to pay the price charged by the seller in any case. That is, $\pi_{c}^{b}=V-p^{l}$ if $\tau$ is

\footnotetext{
${ }^{8}$ In theory, there exists a third type of fraudulent behavior, which is overtreatment. It occurs whenever the expert provides the high quality to a consumer who has the minor problem. When quality is not observed by the consumer -as it is the case in the games we study in this paper- overtreatment is dominated for the seller by overcharging and it is empirically irrelevant in those cases (see Dulleck et al., 2011, for details).
} 
sufficient, and $\pi_{c}^{b}=-p^{l}$ if it is not. In case of no interaction both the consumer and the expert receive an outside value of $o$. Figure 1 presents the structure of this baseline game, excluding the price announcement stage.

\section{Figure 1 about here}

\subsection{Tax evasion}

Taking the baseline game in Figure 1 as starting point, we now modify it in two ways to implement a tax evasion framework. More specifically, we allow the baseline game to be played either with or without taxes. In the taxation variant of the game (denoted $\Gamma_{t}$ ), the monetary payoffs of the two agents change to $\pi_{i}^{t}=\pi_{i}^{b}-t$ for $i=s$, c. For the sake of simplicity, the tax is modeled as a flat payment $t$ imposed on each side of the market whenever a transaction takes place no matter which quality is provided and which price is charged for the good. In the evasion variant of the game (denoted $\Gamma_{e}$ ) the material payoffs of the two players depend upon whether tax evasion is detected or not. In the latter case $\pi_{i}^{e}=\pi_{i}^{b}$, while in the former case $\pi_{i}^{e}=\pi_{i}^{b}-(t+f)$, where $f$ is the fine levied by the tax-authority and $i$ $=s, c$. Whether tax evasion is detected or not depends on the realization of an independent random variable, with the probability of detection being $d$. The sum of all tax payments and penalties levied are multiplied with a factor $r>1$ and are then redistributed equally among all market participants in the manner of a public goods game. To preserve the public good nature of the structure of material payoffs the factor $r$ is chosen such that the individual return of contributing is less than one (i.e., $r / n<1$, where $n$ is the number of market participants).

In order to detect a possible relationship between the revealed intention of an agent to pay or to evade taxes and the way she behaves or the way she is treated by another agent in the market stage of the game we introduce a tax-decision stage in which the seller and his consumer can jointly determine whether they want to play variant $\Gamma_{e}$ or variant $\Gamma_{t}$ of the market game (see Figure 2). We accomplish this by giving the expert and the consumer the possibility of simultaneously and independently expressing their willingness to evade taxes as a binary decision. In what follows the term "tax-dishonest" is used to indicate that a player revealed the intention to evade taxes at this stage, while "tax-honest" means that he or she decided against tax evasion. It is reasonable to assume that no one can be forced to evade taxes. Therefore, we require that tax evasion needs a unanimous consent, i.e., taxes are evaded if and only if both parties of a transaction are tax-dishonest in the tax-decision stage of the game. After this stage, both agents get to know the tax decision of the other player and continue with playing either the $\Gamma_{e}$ or the $\Gamma_{t}$ variant of the market game. 


\section{Figure 2 about here}

Assuming common knowledge that all agents are risk-neutral and exclusively interested in their own material payoff and implementing parameters such that $(1-h) V-p^{h}<o$, the subgame perfect prediction for the market game is that in case of acceptance the expert always provides the low-quality service and charges the price for the high-quality service. Anticipating this, the consumer opts out of the market. Expecting that the market will remain inactive, both parties of a transaction are indifferent between the two options at the taxdecision stage of the game.

\section{EXPERIMENTAL DESIGN}

\subsection{Experimental treatments}

In order to isolate the consequences of different constellations of revealed intentions regarding tax evasion on the behavior of the agents and to identify the causes for these consequences our experiment involves three treatments implemented in a between-subjects design.

In treatment ENDO (for endogenous) participants are asked to express their willingness to evade taxes as a binary decision, as described in the previous section. This is our main treatment, the findings of which we discuss in Section 4. In addition we ran two control treatments, called EXO and SELLER.

In EXO (for exogenous) participants are randomly assigned to either the $\Gamma_{e}$ or the $\Gamma_{t}$ variant of the game. To control for unobserved factors, the data regarding price vectors, problem types, market conditions (taxed or untaxed), and detected instances of tax evasion is held constant across EXO and ENDO. This is done by taking the data observed in the ENDO treatment and implementing it exogenously in the EXO treatment. We will use treatment EXO to examine whether differences in the market behavior of trading partners in different constellations of revealed preferences to evade taxes are caused by the shift in the market environment itself. It might be the case, for instance, that subjects behave differently in an environment where gains from trade are high with high probability and low with low probability (as it is the case in the $\Gamma_{e}$ variant of the market game) as compared to an environment where gains are intermediate with certainty (as it is the case in the $\Gamma_{t}$ variant of the game). In the introduction we referred to this as the cake size effect. 
In the SELLER treatment the power of deciding about tax evasion is entirely on the sellers' side, while consumers are not able to express their intentions regarding tax evasion. This treatment will be used to gain information about the existence of a selection effect (as discussed in the introduction), in particular to shed light on the question whether tax-dishonest sellers are per se more likely to misbehave in credence goods markets. Table 1 summarizes our treatments.

\section{Table 1 about here}

\subsection{Experimental procedures}

At the beginning of each session subjects were randomly assigned to their fixed role as either a seller or a consumer and they were given an initial endowment of 200 experimental currency units (ecu), with 100 ecu being worth 1 euro. In all treatments subjects played 20 periods in a random stranger design within a matching group of eight participants, consisting of four sellers and four consumers. ${ }^{9}$

A consumer's probability of having the major problem was set to $h=0.5$ and the value for the consumer of receiving a sufficient quality was $V=120 \mathrm{ecu}$. The costs for the expert of providing a low-quality service was $c^{l}=20$, and the cost of a high-quality service was $c^{h}=40$. Five price vectors $\left(p^{l}, p^{h}\right)$ from the set $\{(50,60),(50,70),(50,80),(60,80),(70$, $80)\}$ were imposed randomly and with equal frequency. The outside payment $o$ was set to 5 ecu. Note that for those parameters the condition $(1-h) V-p^{h}<o$ is fulfilled for all price constellations and standard theory predicts a complete market breakdown for our experimental market game. Roughly in line with the audit probabilities for non-business individual returns and corporate returns in the US (cf. IRS, 2011) we set the probability of an untaxed transaction being detected to two percent $(d=0.02)$. To keep things simple in the experiment, the tax $t$ as well as the penalty $f$ was set to $10 \mathrm{ecu}$. All taxes and penalties were contributed to a public account with an efficiency factor of 2 , i.e., all payments were doubled and equally distributed among the members of a matching group, implying a marginal per capita return of 0.25 . Payments from the public good were only revealed at the end of the experiment.

\footnotetext{
9 The random stranger design was implemented in order to avoid reputation effects in the buyer-seller interaction. Although it is true that trading partners meet more than once on average and some kind of reputation can emerge at the group level, subjects can never identify who their current partner is, thus excluding reputation formation on the individual level.
} 
At the outset of each session, participants were given plenty of time to read through the instructions (those for treatment ENDO are given in the Appendix) by themselves. Afterwards, the instructions were also read out aloud. The experiment was framed as a decision about tax evasion (and about problems and solutions in a market with buyers and sellers) in order to induce the underlying tax context rather than letting participants choose between abstract lotteries without context. Before the start of the experiment, each participant had to answer a set of control questions and the experiment did not continue until all participants had answered all questions correctly. To get the same number of data points from all experts, an expert was asked to make his provision and charging decision after he received information about the tax attitude of his consumer, but before he received information about the consumer's interaction decision. ${ }^{10}$

We concluded each session with a test eliciting each subject's risk attitudes - which could be an important factor driving tax evading behavior. Each subject was exposed to a series of 10 binary choices between a cash gamble and a safe payoff. While the cash gamble remained the same in all choices - it always yielded either $500 \mathrm{ecu}$ or $0 \mathrm{ecu}$, each with 50 percent probability - the safe payoff increased in steps of $50 \mathrm{ecu}$ from $50 \mathrm{ecu}$ to $500 \mathrm{ecu}$. The 10 binary choices were presented to the subjects one-at-a-time in random order (i.e., each binary decision on an own screen). With the choice data we constructed a variable (called risk factor) defined as the number of times a subject opted for the risky lottery, with higher values thus corresponding to a higher willingness to take risks.

The experiment was conducted computerized at the University of Innsbruck using zTree (Fischbacher, 2007) and recruitment was done via ORSEE (Greiner, 2004). In total, 248 students participated, 80 in each of the treatments ENDO and EXO, and 88 in treatment SELLER. Sessions lasted for about 75 minutes and average earnings were about 11 euros. Each subject took part in only one session, and we excluded subjects with prior experience in credence goods games and tax experiments.

\footnotetext{
${ }^{10}$ Since the strategy method is not used to elicit a seller's provision and charging behavior contingent on the tax decision of the trading partner (which is the main focus of this work) but only for the participation decision, experimenter demand effects or similar objections related to the validity of the strategy method are arguably less of an issue in our design. For discussions of the pros and cons of using the strategy method see, for instance, Casari and Cason (2009), or Brandts and Charness (2011).
} 


\section{RESULTS IN ENDO}

In what follows we define "e-sellers" as sellers who revealed the intention to evade taxes and "t-sellers" as sellers who revealed the intention to pay the tax, and apply the analog definitions for consumers. We will refer to the pool of sellers and buyers who revealed a preference for paying (evading) the tax as "t-agents" ("e-agents"). For future reference we also define the following variables:

- The tax-dishonesty rate is the relative frequency of cases where subjects revealed the intention to evade taxes.

- The interaction rate (IR) is the relative frequency of consumers choosing to enter the market.

- The undertreatment rate (UR) is the ratio of cases where the seller chose to provide the low-quality service to a consumer having the major problem to all cases where the consumer has the major problem.

- The overcharging rate (OR) is the ratio of cases where the seller charged for the highquality service while providing the low-quality service to all cases where a low-quality service was provided.

- Market efficiency is defined as IR·(1-UR), which allows comparing market performance after different outcomes of the tax-decision stage of the game. ${ }^{11}$

The focus of our interest lies in the consequences of different constellations of revealed intentions to pay or evade taxes in treatment ENDO on the subsequent behavior on the credence goods market. We therefore first report the results of this treatment and postpone the discussion of the two control treatments to the next section. As a reminder, the agreement of both trading partners was required to conduct tax evasion in treatment ENDO. Accordingly, we will refer to attempted tax evasion when one of the agents revealed the intention to evade taxes, but the other did not, and we will refer to actual tax evasion when both agents revealed the intention to evade taxes so that the tax was not paid.

Table 2 reports the undertreatment and overcharging rates (i.e., provision and charging decisions by expert sellers) as well as interaction rates (i.e., entry decisions by consumers) and

\footnotetext{
${ }^{11}$ Note that this definition of efficiency does not take into account the amount of the public good provided through tax collection, since our analysis focuses on the welfare effects of tax evasion on the underlying market.
} 
overall market efficiency, broken down by treatment and by configuration of agent types. ${ }^{12}$ We will present our findings in reverse chronological order, following the logic of backwards induction: We discuss the provision and charging behavior of sellers in Subsection 4.1, the participation decision of consumers in 4.2 , the overall market efficiency in 4.3 and the tax evasion decisions in 4.4. In Section 5 we then proceed with an attempt to disentangle the various mechanisms driving our results, along the lines of the various effects outlined in the introduction (the solidarity and the conspiracy effect, the punishment effect, the selection effect, the cake size effect and the anticipation of one or more of these effects).

\section{Table 2 about here}

\subsection{The market game: undertreatment and overcharging}

We begin by analyzing the effects of attempted and actual tax evasion on market outcomes and take a situation with two t-agents (Situation A in Table 2) as a reference. Situations B and $\mathrm{C}$ refer to attempted tax evasion by one of the two agents, while Situation D leads to actual tax evasion. Panel (a) of Table 2 reveals that the provision behavior of expert sellers is most honest when both agents have revealed their willingness to pay taxes in the tax-decision stage (Situation A). Here, the undertreatment rate of 0.43 is lower than in all other situations (and this value is significantly different to the corresponding value in $\mathrm{B}$ and in $\mathrm{D}, p<0.05$ for each comparison). ${ }^{13}$ When being matched with an e-consumer, a t-seller on average significantly increases the UR from 0.43 to 0.58 ( $p<0.05$ ), while an e-seller decreases the UR from 0.65 to 0.57. However, this latter drop in UR is not significantly different from zero. Also, comparing undertreatment in the cases where a seller and a consumer have agreed on evading the tax (Situation D) with the other situations reveals that undertreatment rates in Situation D do not differ significantly from those in situations B and C $(p>0.8)$, but are significantly higher than those in dyads in which both subjects were tax-honest $(p=0.01)$.

Columns (1) and (2) of Table 3 formally test the consequences of interacting with an e-consumer for the two types of sellers. ${ }^{14}$ Column (1) indicates that tax-dishonest consumers have to be prepared for a (weakly) significantly higher probability of undertreatment than

\footnotetext{
${ }^{12}$ Table 2 does not report the results for overtreatment, given that overtreatment is costly from the seller's point of view and does not create any value for the consumer. As it turns out, overtreatment rates were indeed extremely low in all treatments and occurred overall in just $2.4 \%$ of cases with a minor problem.

13 In order to control for the fact that observations within a matching group of eight participants are not independent of each other, all subsequent statistical $p$-values are based on two-sided Wilcoxon signed rank tests based on matching group averages across all twenty periods (unless stated otherwise).

${ }^{14}$ In this and in all subsequent regressions, standard errors are clustered by matching group in order to control for interdependencies within each group.
} 
honest ones when the interaction partner is an honest seller. By contrast, tax-dishonest sellers treat e- and t-consumers more or less the same, as can be seen in column (2).

\section{Table 3 about here}

Result 1: Undertreatment rates are lowest when both agents have opted for paying the tax in the first stage. Tax-dishonest consumers face significantly more undertreatment than taxhonest ones when interacting with an honest seller. Tax-dishonest sellers treat both types of consumers alike.

Overcharging does not result in any changes in efficiency since it is only a matter of redistribution. Table 2 shows that overcharging rates are very high across the board, which leaves little room for significant treatment differences in this fraud dimension. It is still worthwhile noting that overcharging is most frequent when two e-agents interact (Situation D), but the only statistically significant difference is between situations D and C $(p<0.05)$.

Result 2: We observe only small differences in overcharging rates between different types of interacting dyads. The highest overcharging rates occur in the interaction of two taxdishonest agents.

We conclude this subsection with a word on actual tax evasion, i.e., the case in which both agents are tax-dishonest and the transaction goes untaxed. Pooling situations $\mathrm{A}$ to $\mathrm{C}$ and comparing them with $\mathrm{D}$ allows us to address the question whether behavior differs in conditions $\Gamma_{\mathrm{e}}$ and $\Gamma_{\mathrm{t}}-$ or, put differently, to evaluate the impact of actual tax evasion. There is no significant difference in undertreatment rates $(p>0.16)$ between taxed and untaxed markets, while there is a significant difference in overcharging rates $(p=0.02)$. The result for the undertreatment rate is perhaps not surprising since we have argued that attempted tax evasion is already enough to increase misbehavior by sellers compared to mutual tax honesty. When, in addition to attempted tax evasion, actual tax evasion occurs, undertreatment does not increase further because it is already at a high level and also because pairs of taxdishonest agents tend to display slightly lower undertreatment rates than pairs of differentlyminded agents. We will return to this point in Section 5.

\subsection{The market game: interaction rates}

Turning to the consumer's participation decision, a close look at the relevant column of Table 2 reveals that the interaction rate (IR) of 0.85 in Situation A is significantly higher than in all 
other situations ( $p<0.05$ for all pairwise comparisons). Furthermore, consumers differentiate between t-sellers and e-sellers and condition their interaction behavior on the tax decision of the seller. T-consumers, in particular, are much more willing to enter the market if they are interacting with a t-seller than with an e-seller, increasing their IR from 0.64 to 0.85 ( $p<$ 0.05). E-consumers also take their trading partner's tax decision into consideration, however here the effect of meeting a dishonest seller runs into the opposite direction. Comparing Situation B, in which e-consumers meet t-sellers, with Situation D, in which they meet esellers, reveals that e-consumers increase their interaction rate by 7 percentage points when being matched with an e-seller $(p<0.1)$.

These results on consumer behavior are qualitatively confirmed by regressions (3) and (4) of Table 3, which explain the interaction decision of consumers by means of an array of factors, including the tax decision of the seller. To receive more detailed information we ran separate regressions for $\mathrm{t}$ - and e-consumers. The dummy for meeting a tax-dishonest seller shows up with signs in line with the qualitative differences from Table 2 for both types of consumers, again suggesting that t-consumers decrease and e-consumers increase their interaction rates as a response to meeting an e-seller. This effect is significant only for taxhonest consumers and it has a large negative coefficient of -0.22 , mirroring the pronounced differences in interaction rates seen in Table 2 . The other factors influencing the probability of interaction have the expected signs: Anticipating the incentive to overcharge, interaction probabilities decrease in $p^{h}$, while the trend towards more selfish behavior of sellers indicated by Figure 4 below results in a reduction of interaction frequencies over time.

Result 3: Tax-honest consumers decrease their interaction rates significantly when they meet a tax-dishonest seller. Tax-dishonest consumers react in the opposite direction, but this effect is not significant.

\subsection{The market game: overall efficiency}

Combining the interaction and undertreatment rates in different situations to measure market efficiency, defined as IR·(1-UR), we are able to investigate the efficiency loss that arises on the underlying market for credence goods as a consequence of attempted and actual tax evasion. As suggested by the results on undertreatment and interaction rates, efficiency is highest (0.48) in dyads with two tax-honest agents (Situation A in Table 2). This impression is confirmed by statistical tests: We find that efficiency in all other situations is significantly lower $(p<0.05)$ than in Situation A. All deviations from perfect honesty to attempted or 
successful tax evasion hence lead to a drop in efficiency of considerable magnitude, ranging from a drop by one third in Situation D to a drop by more than 50 percent in Situation C.

Result 4: Market efficiency is highest when both agents are tax-honest, but decreases significantly when at least one of the agents has revealed the intention to evade the tax. Attempted tax evasion is thus enough to lead to large efficiency losses.

Whenever tax evasion was attempted (and regardless of whether it was in fact realized through mutual agreement), the market suffered from severe efficiency losses caused by a combination of an increase in the undertreatment rate and a decrease in the interaction frequency. Pooling situations $\mathrm{A}$ to $\mathrm{C}$ and comparing them with $\mathrm{D}$ reveals the efficiency impact of actual tax evasion. The similarity of overall undertreatment and interaction rates in market conditions $\Gamma_{\mathrm{e}}$ and $\Gamma_{\mathrm{t}}$ results in no significant difference in efficiency between the two market conditions $(p>0.24)$, although the difference is in the expected direction and is of quite substantial magnitude. Again, this is not really surprising since we have argued that attempted tax evasion is enough to reduce efficiency compared to mutual tax honesty, through the behavioral responses outlined so far in our results.

\subsection{The tax-decision stage: revealed intentions to evade taxes}

Overall, in 60 percent of cases subjects were tax-dishonest, resulting in a total tax evasion rate of 37 percent (given that the consent of both trading partners is required to actually evade the tax). Tax (dis)honesty is a deliberate and consistent decision for most subjects: 84 percent of the subjects can be classified as either being regularly tax-honest (with tax-honesty rates of three quarters or more) or regularly tax-dishonest (with tax-honesty rates of one quarter or less). Figure 3 reports the distribution of relative frequencies of subjects' tax decisions, broken down by sellers and consumers. A Kolmogorov-Smirnov test for equality in distributions shows no significant difference in tax-honesty of sellers and consumers $(p>$ 0.8 ), even though sellers opt, on average, more often for tax evasion than consumers (63 vs. 57 percent of all decisions). At any rate, both distributions are clearly far from random, suggesting that agents expect to interact on the market later on with positive probability. To get an impression of whether behavior is also stable over time, the black dashed line in Figure 4 depicts the smoothed tax-dishonesty rate over all periods, and exhibits a slight upward trend. 
To get more information on the drivers of behavior in the tax-decision stage of the game we run a probit regression as shown in Table 4. It explains revealed intentions to evade taxes in treatment ENDO by means of the participant type (seller or consumer), the two prices, the period, and idiosyncratic controls for gender, age, and risk attitudes. Contrary to the results of the non-parametric statistical tests, the regression picks up a weakly significant difference between participant types, with sellers being about 12 percentage points more likely than buyers to opt for tax evasion, ceteris paribus. Similar to previous studies such as Baldry (1987) and Bayer and Sutter (2009) we also find a significant effect of gender on the probability of tax evasion, with females exhibiting a lower propensity to be tax-dishonest. Risk attitude shows up insignificantly, implying that we do not find any evidence that risk attitudes are important for tax-honesty in the tax-decision stage.

\section{Table 4 about here}

\section{WHAT IS DRIVING THE RESULTS?}

In the previous section we have seen that market behavior in our main treatment differs remarkably between the four constellations of revealed intentions to evade taxes (i.e., between situations $\mathrm{A}-\mathrm{D}$ in Table 2). However, within the ENDO treatment it was impossible to discriminate between the various effects that might be responsible for the differences.

For instance, we found that the undertreatment rate is only $43 \%$ in Situation A, while (with 58\%) it is 15 percentage points higher in Situation B. This finding is consistent with the existence of a solidarity effect which predicts that tax-honest sellers treat tax-honest customers better than tax-dishonest ones. However, the punishment effect makes exactly the same prediction regarding this comparison. This is not an accident - to the contrary, within the ENDO treatment the solidarity and conspiracy effect on the one hand, and the punishment effect on the other, are simply two sides of the same coin: Solidarity and conspiracy predict better performance in 'symmetric situations' (i.e., in A and in D), while punishment predicts worse performance in 'asymmetric situations' (i.e., in B and in C).

As a second example consider the finding that the undertreatment rate is significantly lower in A (where both parties are tax-honest) than in D (where both are tax-dishonest). This finding could be attributed to the solidarity effect (one would have to argue that it is stronger than the conspiracy effect), to the selection effect (which predicts that more pro-social sellers are not only less inclined to evade taxes but also less willing to defraud consumers), to the cake-size effect (one would have to argue that sellers behave in a more consumer-friendly 
way in an environment where earnings are intermediate with certainty than in the alternative scenario where gains from trade are high with high probability and low with low probability), or to any combination of those effects.

To receive information about the relative importance of the various effects for our findings we will exploit the two control treatments, SELLER and EXO. Panels (b) and (c) in Table 2 report the key variables for those treatments, and Table 5 shows regressions with undertreatment, overcharging and interaction rates as dependent variables and with the seven situations of Table 2 as independent variables (with Situation A as the left-out category).

\section{Table 5 about here}

First we search for evidence of a cake size effect. This effect could be responsible for differences between the untaxed Situation D and all other (taxed) situations in ENDO. The hypothesis would be that behavior differs between markets $\Gamma_{e}$ and $\Gamma_{t}$ due to the sheer change in profits and their probabilities, no matter how tax evasion has come about (in case it has). To check for the existence of a cake size effect we use our EXO treatment where by design the solidarity, conspiracy, punishment and selection effects can play no role, while the cake size effect is potentially present. Specifically, we compare Situation G to Situation H. We find only small and insignificant differences in the provision and charging decisions of sellers across the two market situations. The overcharging rate is practically identical in $\mathrm{G}$ and $\mathrm{H}$. The undertreatment rate increases slightly from 0.59 in taxed markets to 0.62 in untaxed markets, but this difference is insignificant based on an F-test (Situation $G=$ Situation $H$, post-estimation based on column 1 of Table 5). Accordingly, we conclude by stating that we fail to find evidence for a cake size effect in the provision and charging decisions of sellers, which - if present - could account for some of the differences in ENDO.

So far, we cannot disentangle the selection effect - i.e., the effect of self-selection by sellers into the underground economy - from the reaction of a seller to a consumer's tax decision, i.e., we cannot exclude the possibility that tax-evading sellers are per se more likely to undertake fraudulent behavior regardless of the tax attitude of consumers. To check for the presence of a selection effect (on top of the insignificant cake size effect) we use our SELLER treatment where by design the solidarity, conspiracy and punishment effects can play no role, while the selection and the cake size effect are potentially present. Specifically, we compare Situation E in Table 2 (where the seller has self-selected into the taxed economy) to Situation $\mathrm{G}$ (where the seller was randomly assigned to the taxed economy) and Situation F (where the seller has self-selected into the untaxed economy) to Situation $\mathrm{H}$ (where the seller was 
randomly assigned to the untaxed economy). Selection predicts higher undertreatment and overcharging rates in $\mathrm{G}$ than in $\mathrm{E}$ and in $\mathrm{F}$ than in $\mathrm{H}$. Indeed, all four comparisons (two comparisons for each of the two fraud dimensions) are qualitatively in line with seller selection - undertreatment, for instance, is much higher among e-sellers in SELLER than under exogenously imposed tax evasion (70\% vs. 62\%). In terms of the relevant F-tests in Table 5 , the differences are generally insignificant with the notable exception of significantly higher overcharging rates in situation $\mathrm{F}$ than in $\mathrm{H}(97 \%$ vs. $92 ; p<0.05$, F-test based on column 2 of Table 5). This indicates that those sellers who self-select into the untaxed economy are more likely to overcharge their customers.

The solidarity effect and the conspiracy effect refer to the possibility that sellers may reserve better treatment for consumers of the same type. As we have defined those terms in the introduction, solidarity may drive behavior in the relationship between t-sellers and $\mathrm{t}$ consumers, while conspiracy might be relevant in the interaction between e-sellers and econsumers, and both can alternatively be thought of as in-group favoritism. To check for the existence of a solidarity or a conspiracy effect we compare Situation A from treatment ENDO to Situation E from treatment SELLER and Situation D from treatment ENDO to Situation F from treatment SELLER. Solidarity between two tax-honest agents predicts that sellers cheat less in A than in E, because in A they are matched with a consumer of the same type, whereas in E nothing is known about the type of the consumer. For the same reason, conspiracy between two tax-dishonest agents predicts that undertreatment and overcharging will be less common in D (where nothing is known about the consumer's type) than in F. While we have seen that overcharging frequencies are almost at a corner in every situation - and in this case higher in $\mathrm{D}$ than in $\mathrm{F}$, contrary to the conspiracy hypothesis - the qualitative differences for undertreatment are fully in line with the existence of both a solidarity and a conspiracy effect. Undertreatment is less common in A than in E and in D than in F. Based on column 1 of Table 5, both F-tests (Situation $A=$ Situation $E$ and Situation $D=$ Situation $F$ ) point to weakly significant differences $(p<0.1)$.

The punishment effect predicts that fraud is more prevalent in situations where the seller knows he is matched with someone of a different tax attitude than in situations where he does not have this information. To check for the existence of a punishment effect we compare Situation B from treatment ENDO to Situation E from treatment SELLER and Situation C from treatment ENDO to Situation F from treatment SELLER (here we exploit the fact that the cake size effect was found to be unimportant). Punishment predicts more consumer-friendly behavior in $\mathrm{E}$ than in $\mathrm{B}$ (where the seller knows that the consumer is of a different type) and 
more consumer-friendly behavior in $\mathrm{F}$ than in $\mathrm{C}$ (for the same reason). The corresponding differences in undertreatment and overcharging rates are either very small or in the "wrong" direction, such as the comparison between the $65 \%$ undertreatment rate in $\mathrm{C}$ and the $70 \% \mathrm{UR}$ in F, and the F-tests in Table 5 show that the differences are always insignificant. Hence, we find no evidence to support the presence of a punishment effect in our experiment. We summarize the findings of this section as:

Result 5: We find evidence for the existence of a solidarity effect between two tax-honest agents and a conspiracy effect between two tax-dishonest agents, leading to less fraud when agents reveal the same tax attitude. We also find some evidence for the existence of a selection effect, with tax-dishonest sellers being more likely to overcharge their customers, but no evidence for the existence of a punishment effect or a cake size effect.

In this section's analysis we have so far mainly dealt with the various effects driving the provision and charging behavior of sellers, while remaining silent about the behavior of consumers and the resulting interaction rates. The reason is that our design does not allow us to cleanly identify the relative roles of the many effects that might be driving the decision to enter the market or not. In particular, entry decisions by consumers can be driven by a solidarity, a conspiracy, a punishment or a cake-size effect, but also by the consumer's expectation of (some of) these effects affecting their partners as sellers. To give an example of this, let us compare the interaction rates in situations A and C. The fact that interaction is much more frequent in A than in $\mathrm{C}$ may be driven by a solidarity effect (t-consumers reward t-sellers' tax-honesty in A by increasing their propensity to enter the market), a punishment effect ( $\mathrm{t}$-consumers punish e-sellers' tax-dishonesty in $\mathrm{C}$ by decreasing their propensity to enter), or an anticipation of a number of different things: Anticipation of less (more) fraud by the seller in A (in C) due to the solidarity (punishment) effect on the seller's side, or anticipation of more fraud in $\mathrm{C}$ due to the perceived selection effect - in this latter case, the consumer perceives the seller's tax evasion decision as a signal of his preferences and of the resulting provision and charging behavior. Similarly, the higher interaction rate in D than in B may be driven by the conspiracy effect, the punishment effect, or by the consumer's anticipation (e.g., if consumers hope for better treatment in D due to conspiracy from the seller).

Our controls are of limited help in disentangling those effects. For instance, following the line of argument that we used for undertreatment, solidarity predicts higher interaction rates in $\mathrm{A}$ than in $\mathrm{E}$ and conspiracy predicts higher interaction in $\mathrm{D}$ than in $\mathrm{F}$. We do find 
significant differences in both of these comparisons $(p<0.05$; F-tests based on column 3 of Table 5), which is consistent with the existence of a solidarity and a conspiracy effect in the consumers' interaction decisions. At the same time, however, consumers may interact more frequently in A and in D because they expect the seller to be driven by the solidarity or the conspiracy effect in these situations. This issue could potentially be addressed by eliciting consumers' beliefs about the behavior of the seller or by running a number of additional control treatments. Given that the main focus of our paper is on the interplay between revealed intentions to pay or evade taxes and provision and charging behavior in the underlying credence goods market, we leave this an open question for future research.

\section{CONCLUSION}

The channels through which tax evasion can be detrimental for welfare are intricate. We have experimentally investigated the effects of revealed intentions to pay or evade taxes on the performance of a particular kind of market that is prone to inefficiencies in trade. Participants in a credence goods market were given the opportunity to reveal their intentions regarding tax evasion before the actual transaction took place. Only when both the seller and the consumer opted for tax evasion, was the transaction actually concealed from the tax authority.

We are contributing to the literature on tax evasion by demonstrating that the phenomenon is detrimental not only because it yields an unfair distribution of the overall tax burden, increases the excess burden of collecting a given tax revenue, wastes resources when taxpayers try to conceal and tax authorities try to detect tax evasion, imposes uncertainty on risk-averse evaders and distorts competition, but also because of its negative impact on the efficiency of interaction in the underlying market. In transactions in which at least one partner was tax-dishonest, efficiency was up to 50 percent lower than in a constellation with exclusively tax-honest agents. This difference is driven by higher undertreatment frequencies and lower interaction rates in markets in which tax evasion was attempted or successfully conducted. We found that the efficiency drop in untaxed markets is hardly driven by the change in market conditions. Rather, efficiency losses arise mainly due to the fact that subjects who prefer to pay taxes react negatively to the intent of a trading partner to evade them by an increased frequency of undertreatment (in the case of sellers) and a decreased frequency of interaction (in the case of consumers). This is in line with our initial conjecture about the existence of a solidarity effect between two tax-honest agents that seems to reduce the undertreatment rate and increase the interaction rate in pairs of tax-honest market participants. Although we also find evidence for a conspiracy effect between two tax- 
dishonest agents, which ceteris paribus would lead to more consumer-friendly behavior in the underground sector, consumers do not really profit from that effect because it is almost entirely cancelled out by a selection effect that causes more selfish sellers to self-select into the underground sector.

Besides the main insight of the paper on the impact of attempted and actual tax evasion on market efficiency, our results also suggest a lesson for consumers. Specifically, they suggest that consumers are well advised to be cautious of proposing to evade taxes in situations in which a seller has an informational advantage over the consumer. If the seller is tax-honest then he might treat the consumer worse because he has less scruple to defraud a tax-dishonest than a tax-honest consumer, due to the fact that he does not identify himself with a tax-dishonest person. In this case, proposing tax evasion leads to deteriorated service without any compensating benefit (given that tax evasion requires mutual consent). In the alternative case where the seller agrees to conceal the transaction, the myopic gain of the evaded tax may easily be canceled out by the deteriorated service provision resulting from the fact that a tax-dishonest seller is more likely to commit fraud in the first place. This latter statement is supported by our finding that selfish sellers tend to self-selected into the shadow economy. So, before agreeing to a transaction it seems advisable for a consumer to try to elicit the tax attitude of the seller who has the power to commit fraud and to abstain from a purchase if she discovers the intention on the seller's side to evade taxes. 
Acknowledgements: We thank Kai Konrad and participants at the X. Tax Day of the Max Planck Institute for Tax Law and Public Finance for helpful comments. Financial support from the Austrian Science Fund (FWF) through grant numbers P20796 and P22669 is gratefully acknowledged. 


\section{REFERENCES}

Allingham, M. G., Sandmo, A. (1972), Income tax evasion: A theoretical analysis. Journal of Public Economics 1: 323-338.

Alm, J., McClelland, G., Schulze, W. (1992), Why do people pay taxes? Journal of Public Economics 48: 21-38.

Andreoni, J., Erard, B., Feinstein, J. (1998), Tax compliance. Journal of Economic Literature 36: $818-860$.

Baldry, J. C. (1986), Tax evasion is not a gamble: A report on two experiments. Economics Letters 22: 333-335.

Baldry, J. C. (1987), Income tax evasion and the tax schedule: Some experimental results. Public Finance 42: 357-383.

Bayer, R.-C. (2006), A Contest with the Taxman - The Impact of Tax Rates on Tax Evasion and Wastefully Invested Resources. European Economic Review 50: 1071-1104.

Bayer, R.-C., Sutter, M. (2009), The excess burden of tax evasion - an experimental detection-concealment contest. European Economic Review 53: 527-543.

Beck, A., Kerschbamer, R., Qiu, J., Sutter, M. (2013), Shaping beliefs in experimental markets for expert services: Guilt aversion and the impact of promises and moneyburning options. Games and Economic Behavior 81: 145-164

Boadway, R., Marceau, N., Mongrain, S. (2002), Joint tax evasion. Canadian Journal of Economics 35: 417-435.

Brandts, J., Charness, G. (2011), The strategy versus the direct-response method: A first survey of experimental comparisons. Experimental Economics 14: 375-398.

Casari, M., Cason, T. (2009), The strategy method lowers measured trustworthy behavior. Economics Letters 103: 157-159.

Chang, J., Lai, C. (2004), Collaborative tax evasion and social norms: Why deterrence does not work. Oxford Economic Papers 56: 344-368.

Charness, G., Rigotti, L., Rustichini, A. (2007), Individual behavior and group membership. American Economic Review 97: 1340-1352.

Clotfelter, C. (1983), Tax evasion and tax rates: An analysis of individual returns. Review of Economics and Statistics 65: 363-373.

Dulleck, U., Kerschbamer, R. (2006), On doctors, mechanics, and computer specialists: The economics of credence goods. Journal of Economic Literature 44: 5-42. 
Dulleck, U., Kerschbamer, R., Sutter, M. (2011). The economics of credence goods: on the role of liability, verifiability, reputation and competition. American Economic Review 101(2): 526-555.

Erard, B., Feinstein, J. S. (1994), The role of moral sentiments and audit perceptions in tax compliance. Public Finance 49, 70-89.

Feldstein, M. (1999), Tax avoidance and the deadweight loss of the income tax. The Review of Economics and Statistics 81: 674-680.

Feinstein, J.S. (1991), An econometric analysis of income tax evasion and its detection. RAND Journal of Economics 22: 14-35.

Fischbacher, U. (2007), z-tree: Zurich toolbox for ready-made economic experiments. Experimental Economics 10: 171-178.

Frey, B., Torgler, B. (2007), Tax morale and conditional cooperation. Journal of Comparative Economics 35: 136-159.

Götte, L., Huffman, D., Meier, S., Sutter, M. (2012), Competition between organizational groups: Its impact on altruistic and anti-social motivations. Management Science 58: 948-960.

Gordon, J. P. P. (1989), Individual morality and reputation costs as deterrents to tax evasion. European Economic Review 33: 797-805.

Greiner, B. (2004). An Online Recruiting System for Economic Experiments.” In: Kurt Kremer, Volker Macho (eds.). Forschung und wissenschaftliches Rechnen 2003. GWDG Bericht 63, Goettingen: Gesellschaft fuer wissenschaftliche Datenverarbeitung: 79-93.

Huck, S., Lünser, G., Tyran, J.-R., 2010. Consumer networks and firm reputation: A first experimental investigation. Economic Letters 108: 242-244.

Huck, S., Lünser, G., Tyran, J.-R., 2012. Competition fosters trust. Games and Economic Behavior 76: 195-209.

Huck, S., Lünser, G., Tyran, J.-R., 2013. Price competition and reputation in markets for experience goods: An experimental study. Discussion Paper No. SP II 2013-312, Wissenschaftszentrum Berlin für Sozialforschung, Abteilung Ökonomik des Wandels.

Kleven, H. J., Knudsen, M.B., Kreiner, C.T., Pedersen, S., Saez, E. (2011), Unwilling or unable to cheat? Evidence from a tax audit experiment in Denmark. Econometrica 79: $651-692$.

Konrad, K., Qari, S. (2012), The last refuge of a scoundrel? Patriotism and tax compliance. Economica 79: 516-533. 
OECD (2004), Informal Employment and Promoting the Transition to a Salaried Economy. OECD Employment Outlook, Chapter 5. Organization for Economic Co-operation and Development, Paris.

Reinganum, J., Wilde, L. (1985), Income tax compliance in a principal-agent framework. Journal of Public Economics 26: 1-18.

Schneider, F., Enste, D. H. (2000), Shadow economies: Size, causes, and consequences, Journal of Economic Literature 38: 77-114.

Slemrod, J. (2007), Cheating ourselves: The economics of tax evasion. Journal of Economic Perspectives 21: 25-48.

Spicer, M., Becker, L. (1980), Fiscal inequity and tax evasion: An experimental approach. National Tax Journal 33: 171-175.

Strand, J. (2005), Tax distortions, household production, and black-market work. European Journal of Political Economy 21: 851-871.

Torgler, B. (2002), Speaking to theorists and searching for facts: Tax morale and tax compliance in experiments. Journal of Economic Surveys 16: 656-683.

Torgler, B. (2004), Moral suasion: An alternative tax policy strategy? Evidence from a controlled field experiment in Switzerland. Economics of Governance 5: 235-253

Yitzhaki, S. (1979), A note on optimal taxation and administrative costs. American Economic Review 69: 475-480.

Yitzhaki, S. (1987), On the excess burden of tax evasion. Public Finance Quarterly 15: 123137. 


\section{TABLES AND FIGURES}

Table 1: Experimental treatments

\begin{tabular}{lll}
\hline treatment & tax evaded if & $\mathrm{N}$ \\
\hline ENDO & both are tax-dishonest & 80 \\
SELLER & seller is dishonest & 88 \\
EXO & exogenously imposed & 80 \\
\hline \hline
\end{tabular}

Table 2: Market behavior in treatments ENDO, EXO, and SELLER.

\begin{tabular}{lclllllll}
\hline \hline situation & seller & consumer & cond. & freq. & UR & OR & IR & EFF \\
\hline Panel (a): ENDO & & & & & & & \\
\hline $\mathrm{A}(E N D O)$ & t-seller & t-consumer & $\Gamma_{t}$ & 0.17 & 0.43 & 0.93 & 0.85 & 0.48 \\
$\mathrm{~B}(E N D O)$ & t-seller & e-consumer & $\Gamma_{t}$ & 0.20 & 0.58 & 0.91 & 0.67 & 0.28 \\
$\mathrm{C}(E N D O)$ & e-seller & t-consumer & $\Gamma_{t}$ & 0.26 & 0.65 & 0.91 & 0.64 & 0.23 \\
$\mathrm{D}(E N D O)$ & e-seller & e-consumer & $\Gamma_{e}$ & 0.37 & 0.57 & 0.98 & 0.74 & 0.32
\end{tabular}

Panel (b): SELLER

\begin{tabular}{lllllllll}
\hline $\mathrm{E}($ SELLER $)$ & $\mathrm{t}$-seller & $\mathrm{n} / \mathrm{a}$ & $\Gamma_{t}$ & 0.36 & 0.56 & 0.88 & 0.68 & 0.30 \\
$\mathrm{~F}($ SELLER $)$ & e-seller & $\mathrm{n} / \mathrm{a}$ & $\Gamma_{e}$ & 0.64 & 0.70 & 0.97 & 0.59 & 0.18
\end{tabular}

Panel (c): EXO

\begin{tabular}{llllllll}
\hline $\mathrm{G}(E X O)$ & tax paid exogenously & $\Gamma_{t}$ & 0.63 & 0.59 & 0.92 & 0.71 & 0.29 \\
$\mathrm{H}(E X O)$ & tax evaded exogenously & $\Gamma_{e}$ & 0.37 & 0.62 & 0.92 & 0.72 & 0.27
\end{tabular}

Notes. Market behavior after different outcomes of the tax-decision stage. UR (OR) represents the undertreatment (overcharging) rate and IR the interaction rate. 'freq.' represents the frequency of occurrence of a certain situation, 'cond.' the resulting market condition (taxed or untaxed), and 'EFF' the resulting market efficiency calculated as IR.(1-UR). 
Table 3: Undertreatment rates and interaction rates, treatment $E N D O$

(1)

(2)

(3)

(4)

\begin{tabular}{|c|c|c|c|c|}
\hline $\begin{array}{l}\text { dependent } \\
\text { variable }\end{array}$ & undertreatment & undertreatment & interaction & interaction \\
\hline used data & t-sellers & e-sellers & $\mathrm{t}$-consumers & e-consumers \\
\hline meeting an e- & & & $-0.220 * * *$ & 0.080 \\
\hline seller & & & $(0.032)$ & $(0.064)$ \\
\hline meeting an e- & $0.191 *$ & -0.099 & & \\
\hline consumer & $(0.107)$ & $(0.097)$ & & \\
\hline \multirow[t]{2}{*}{$p^{l}$} & 0.008 & 0.003 & $0.007 *$ & $-0.007 * *$ \\
\hline & $(0.006)$ & $(0.004)$ & $(0.004)$ & (0.004) \\
\hline \multirow[t]{2}{*}{$p^{h}$} & -0.007 & $-0.008 *$ & $-0.016 * *$ & $-0.009 *$ \\
\hline & $(0.007)$ & $(0.005)$ & $(0.008)$ & $(0.005)$ \\
\hline \multirow[t]{2}{*}{ period } & $0.032 * * *$ & $0.011 * *$ & $-0.017 * * *$ & $-0.008 *$ \\
\hline & $(0.007)$ & (0.004) & $(0.003)$ & $(0.004)$ \\
\hline \multirow[t]{2}{*}{ female } & -0.075 & 0.047 & $-0.118 * *$ & 0.003 \\
\hline & $(0.020)$ & $(0.130)$ & $(0.063)$ & $(0.055)$ \\
\hline \multirow[t]{2}{*}{ age } & -0.031 & -0.029 & -0.006 & -0.001 \\
\hline & $(0.019)$ & $(0.018)$ & $(0.013)$ & (0.008) \\
\hline \multirow[t]{2}{*}{ risk factor } & -0.010 & -0.055 & 0.012 & 0.028 \\
\hline & $(0.068)$ & $(0.076)$ & $(0.036)$ & $(0.025)$ \\
\hline observations & 154 & 246 & 343 & 457 \\
\hline
\end{tabular}

dependent

undertreatment

ndertreatment

(1)

meeting an $e$ -

$-0.220 * * *$

(0.064)

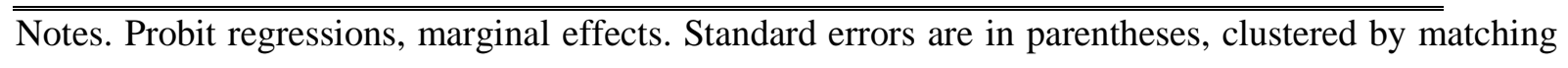
group. *** $p<0.01, * * p<0.05, * p<0.1$. 
Table 4: Tax decisions, treatment ENDO.

\begin{tabular}{ll}
\hline \hline dependent variable & tax-dishonesty \\
\hline seller & $0.122 *$ \\
& $(0.075)$ \\
$p^{l}$ & 0.001 \\
& $(0.001)$ \\
$p^{h}$ & -0.001 \\
& $(0.001)$ \\
period & 0.002 \\
& $(0.003)$ \\
female & $-0.214 * *$ \\
& $(0.084)$ \\
age & 0.010 \\
& $(0.011)$ \\
risk factor & -0.021 \\
\hline Notes. Probit regressions, marginal effects. Standard errors are in & $(0.035)$ \\
observations & 1,600 \\
\hline
\end{tabular}


Table 5: Undertreatment, overcharging and interaction rates, all treatments.

(1)

dependent variable undertreatment
(2)

(3)

\begin{tabular}{|c|c|c|c|}
\hline \multirow[t]{2}{*}{$\overline{p^{l}}$} & 0.003 & $-0.004 * * *$ & 0.001 \\
\hline & $(0.002)$ & $(0.001)$ & $(0.002)$ \\
\hline \multirow[t]{2}{*}{$p^{h}$} & $-0.007 * * *$ & 0.001 & $-0.008 * * *$ \\
\hline & $(0.002)$ & $(0.001)$ & $(0.002)$ \\
\hline \multirow[t]{2}{*}{ period } & $0.009 * * *$ & $0.003 * * *$ & $-0.013 * * *$ \\
\hline & $(0.003)$ & $(0.001)$ & $(0.002)$ \\
\hline \multirow[t]{2}{*}{ female } & 0.014 & 0.027 & 0.007 \\
\hline & $(0.066)$ & $(0.024)$ & $(0.028)$ \\
\hline \multirow[t]{2}{*}{ age } & -0.018 & 0.000 & $-0.009 *$ \\
\hline & $(0.012)$ & $(0.002)$ & $(0.005)$ \\
\hline \multirow[t]{2}{*}{ risk factor } & -0.005 & -0.000 & 0.018 \\
\hline & $(0.028)$ & $(0.007)$ & $(0.013)$ \\
\hline \multirow[t]{2}{*}{ Situation B } & $0.160 *$ & -0.007 & $-0.240 * * *$ \\
\hline & $(0.082)$ & $(0.031)$ & $(0.068)$ \\
\hline \multirow[t]{2}{*}{ Situation $C$} & $0.193 *$ & 0.001 & $-0.238 * * *$ \\
\hline & $(0.086)$ & $(0.038)$ & $(0.027)$ \\
\hline \multirow[t]{2}{*}{ Situation D } & $0.120 *$ & $0.044 * *$ & $-0.145 * *$ \\
\hline & $(0.063)$ & $(0.016)$ & $(0.071)$ \\
\hline \multirow[t]{2}{*}{ Situation E } & $0.148 *$ & -0.035 & $-0.193 * *$ \\
\hline & $(0.077)$ & $(0.053)$ & $(0.090)$ \\
\hline \multirow[t]{2}{*}{ Situation F } & $0.268 * * *$ & 0.038 & $-0.292 * * *$ \\
\hline & $(0.061)$ & $(0.023)$ & $(0.082)$ \\
\hline \multirow[t]{2}{*}{ Situation $G$} & $0.171 * * *$ & 0.006 & $-0.170 * *$ \\
\hline & $(0.044)$ & $(0.031)$ & $(0.083)$ \\
\hline \multirow[t]{2}{*}{ Situation $H$} & $0.176 *$ & -0.003 & $-0.174 *$ \\
\hline & $(0.079)$ & $(0.035)$ & $(0.097)$ \\
\hline observations & 1,240 & 1,962 & 2,480 \\
\hline
\end{tabular}

Notes. Probit regressions, marginal effects. Standard errors are in parentheses, clustered by matching group. ${ }^{* * *} p<0.01, * * p<0.05, * p<0.1$. 
Figure 1: Structure of the baseline game representing a credence good situation

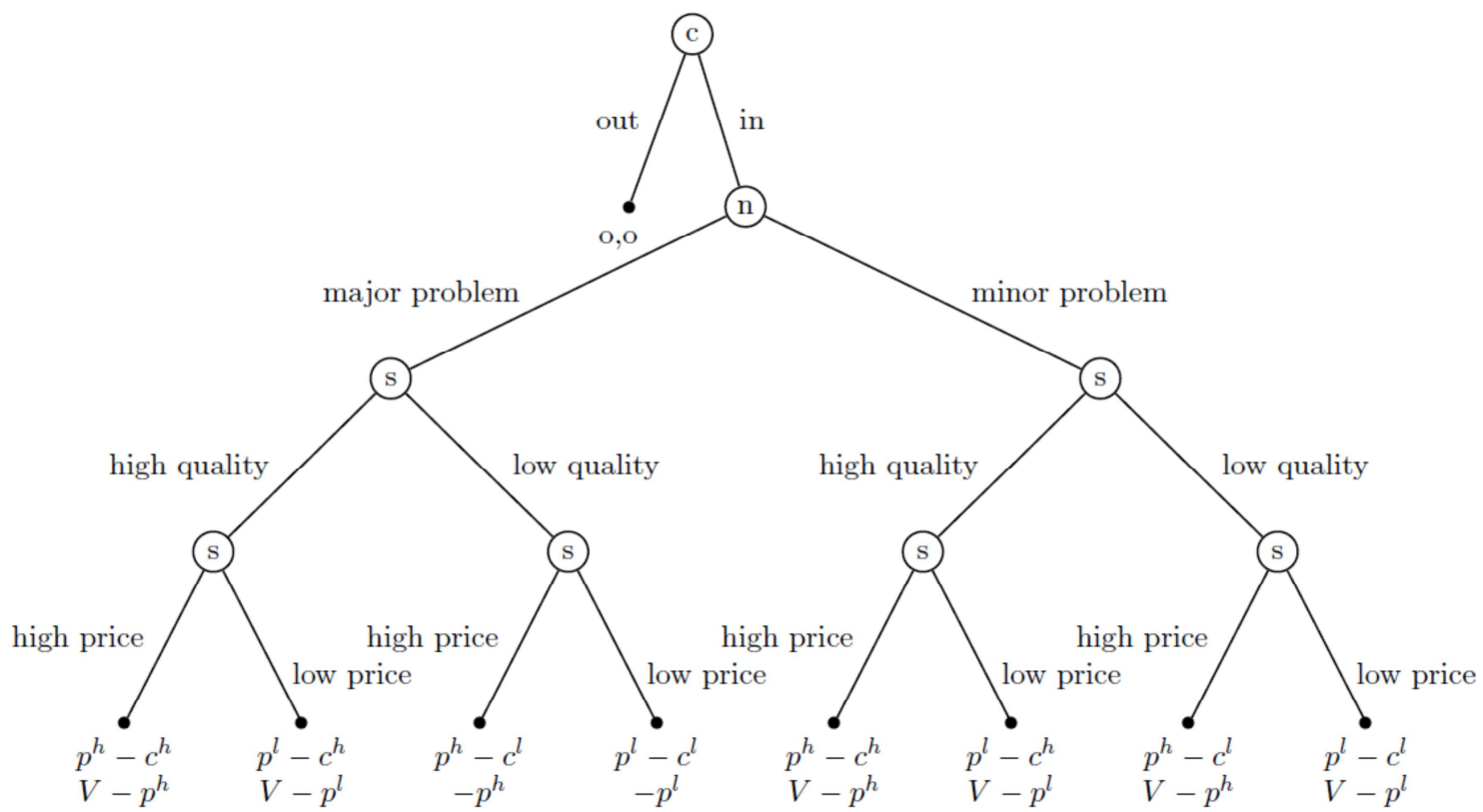

Figure 2: Tax-decision stage

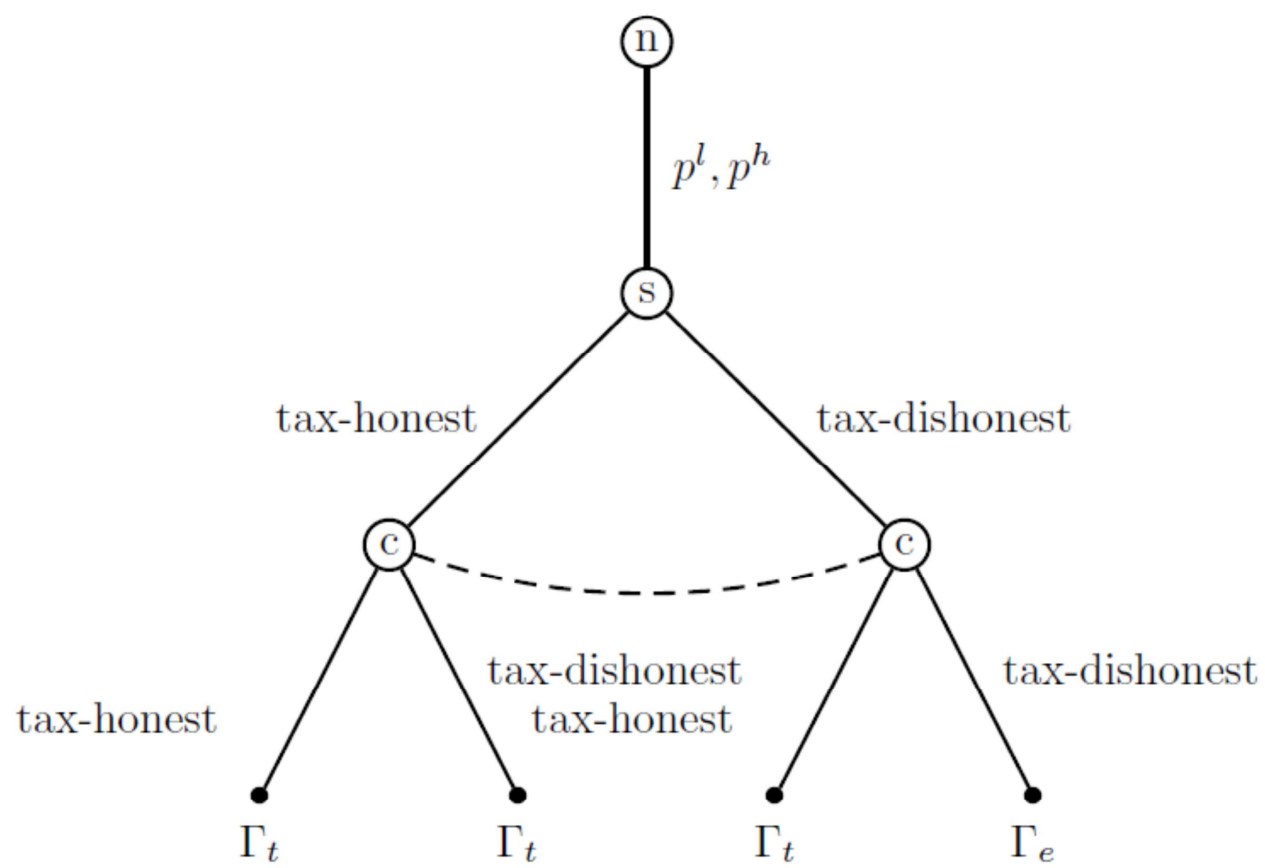


Figure 3: Tax-dishonest decisions per subject in ENDO.

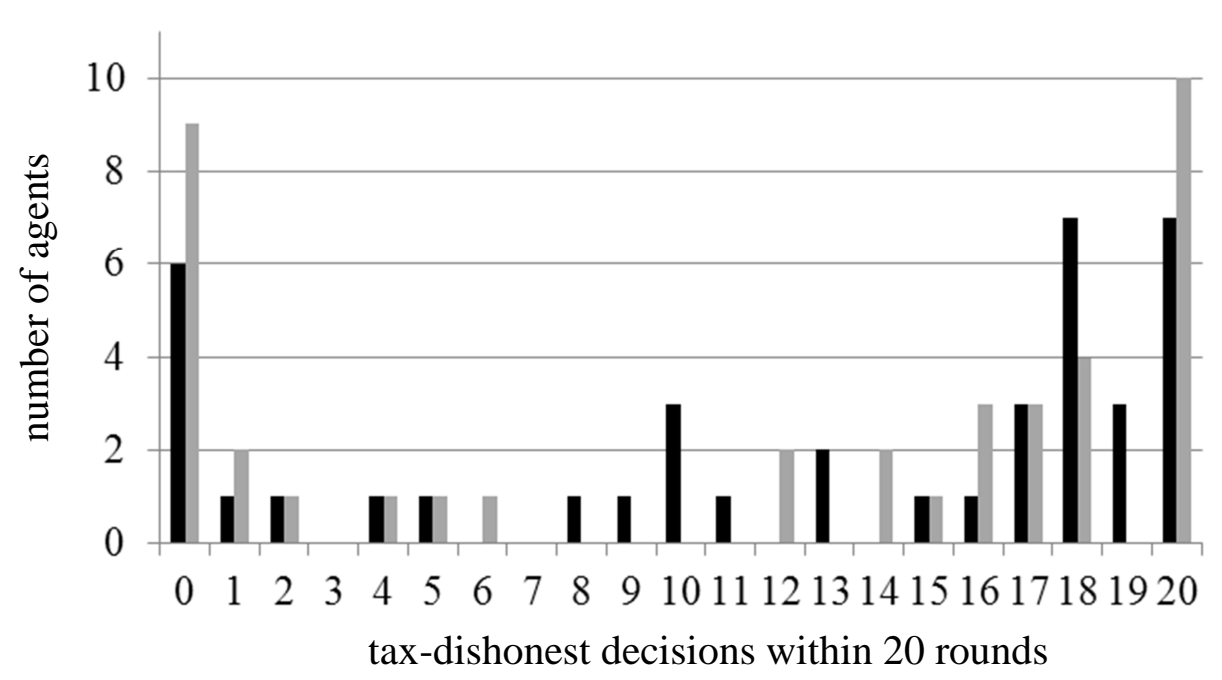

Note. Black (gray) bars indicate sellers (consumers).

Figure 4: Behavior over time in treatment ENDO

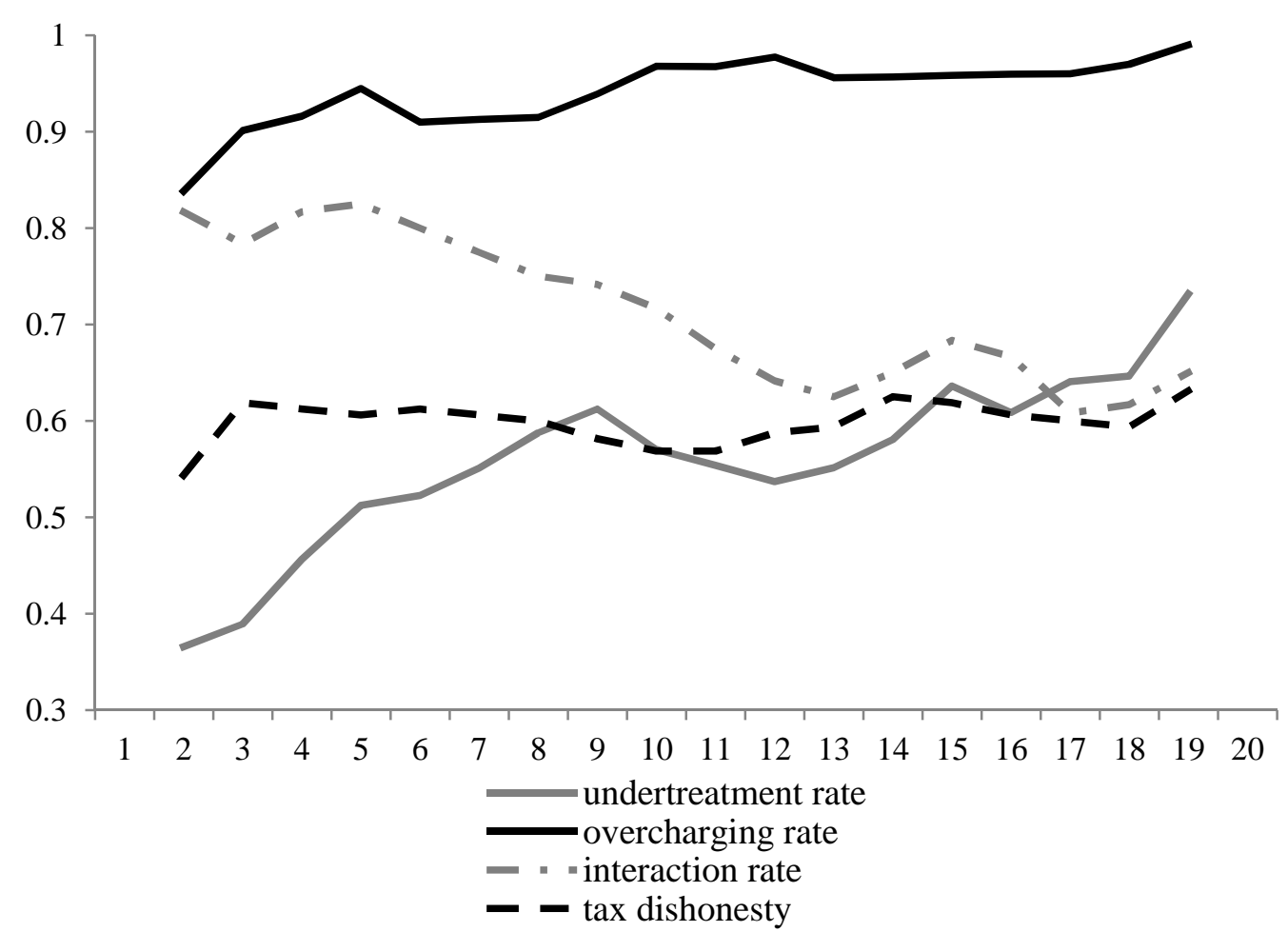

Note. Smoothed by calculating 3-period moving averages 


\section{APPENDIX - Not intended for publication}

\section{INSTRUCTIONS FOR TREATMENT ENDO [translated from German]}

Thank you for participating in this experiment. Please switch off your mobile phones and audio devices. Please do not talk to any other participant until the experiment is over. If you have a question please raise your hand. One of the experimenters will then come and answer your question.

\section{General remarks}

The aim of this experiment is to explore choice behavior. During this experiment you and the other participants will be asked to make decisions. Your earnings will depend on your decisions and the decisions of the other participants. You will receive your payment anonymously and in cash. All participants receive the same information. All of your decisions and answers will be treated confidentially and anonymously. Please consider all expressions as gender neutral.

\section{Rounds and roles}

This experiment consists of $\mathbf{2 0}$ rounds, each of the 20 rounds consists of the same sequence of decisions. This means that each round has the same structure. There are 2 roles in this experiment: Sellers and buyers. At the beginning of the experiment you will be randomly assigned to one of these two roles. On the first screen of the experiment you will see which role you are assigned to. This role stays the same throughout the experiment.

A seller always interacts with a buyer. In each round pairs of participants, consisting of a seller and a buyer, will be determined randomly in each round. At the beginning of the experiment you will be assigned to a group consisting of 8 participants, in which the matching is done.

\section{In each round you face the following situation:}

The buyer has one of two possible problems, but does not know the exact type of her problem: She only knows that she has either problem I or problem II. Both problems are equally likely. The problem of a buyer is randomly determined in each round and is only known to the seller who currently interacts with him. The seller can now sell a solution to the 
buyer, either solution I or solution II. Depending on the chosen solution costs occur for the seller: solution I costs him 20 points, solution II costs him 40 points.

For this solution, the seller can either charge a price from the buyer, where he can choose between the "price of solution I" and the "price of solution II". Those prices are randomly determined in each round and are known to both players. The seller can combine solutions and prices as desired, i.e. if the seller chooses e.g. Solution I, he can either charge the "price of solution I" or the "price of solution II".

The solution sold by the seller to the buyer can either solve the problem of the buyer or not. Solution II solves problems I and II. Solution I only solves problem I. The following table shows when a problem is solved and when it is not:

\begin{tabular}{|l|l|l|l|}
\hline & seller chooses & solution I & solution II \\
\hline buyer has & & & \\
\hline problem I & & problem solved & problem solved \\
\hline problem II & & problem not solved & problem solved \\
\hline
\end{tabular}

It follows that a problem remains unsolved if the buyer has problem II and the seller chooses solution I. The buyer receives 120 points in this round if his problem was solved. If the solution is not sufficient the buyer receives no points in this round. Still, the price the seller charges for his solution has to be paid by the buyer in any case. The seller's earnings do not depend on whether the problem is solved or not.

The buyer will neither be informed about the problem he had, nor will he be informed about the solution the seller chose. He will only be told the price he has to pay to the seller (either the "price of solution I" or the "price of solution II") and whether his problem was solved or not.

\section{Taxes}

The sale of a solution is taxed by the government. If a solution is sold, the seller as well as the buyer each has to pay 10 points to the government. This amount does not depend on which solution the seller chose, which price he charges or which prices have been determined. [In each round it wil be automatically determined whether you and your seller (buyer) evade or pay the tax.]

At the beginning of each round you have [a seller has] the possibility to vote for paying the tax or evading the tax. This is done in the following way. The seller and the buyer decide 
simultaneously (i.e., independently and unobserved by the other participant) if they want to evade or pay the tax. After the seller and the buyer decided, both get to know the decision of the other participant. [this paragraph was not quoted in treatment EXO]

- If both voted for tax evasion [replaced by: If it was determined that you evade the tax] [replaced by: If he decided to evade the tax], both the seller and the buyer save the tax of 10 points and the tax will not be deducted from their payment in this round. Tax evasion is discovered with a probability of $2 \%$ (i.e., 2 out of 100 cases) by the government. In this case, 20 points will be deducted from the seller's well as from the buyer's earnings at the end of the period if a solution was sold.

- If at least one of the both voted for paying the tax [replaced by: If it was determined that you pay the tax] [replaced by: If he decided to pay the tax], this round will be taxed and the tax of 10 points will be subtracted from each at the end of the period, if a solution is sold.

In other words, in order to evade taxes the seller as well as the buyer has to agree to evade the tax. As soon as at least one of them refuses, the tax is automatically paid by both if a solution is sold. [this paragraph was not quoted in treatment EXO or in treatment SELLER]

All taxes and fines paid by the members of your group of eight during the course of all 20 periods are collected by the government. The government doubles this amount at its own expense and redistributes this amount equally among all participants of your group of eight (i.e., each member of your group of eight receives exactly the same amount from the government).

\section{Sequence of a round}

1) Pairs, consisting of a seller and a buyer, are randomly determined.

2) Seller and buyer get to know the „price of solution I” and the ,price of solution II” which were determined for this round.

3) The seller and the buyer simultaneously and independently vote for or against evading the tax of 10 points per person. The result is told both as soon as both decided. [replaced by: It is automatically determined whether you and your seller pay or evade the tax.] [replaced by: The seller decides for or against evading the tax of 10 points per person. The result is told to the buyer as soon as the seller decided.] 
4) The buyer then hast two possibilities:

a) The buyer can opt out in this round. Then, both the seller and the buyer receive 5 points for this round. In this case no taxes have to be paid.

b) The buyer can continue with buying a solution from the seller.

5) Independently of the decision of the buyer in stage 4) the seller gets to know the problem of the buyer (I or II). He then chooses a solution (I or II) and charges either the ,price of solution I” or the ,price of solution II". Only afterwards he learns how the buyer decided in stage 4). If the buyer decided to buy a solution the decisions of the seller in this stage are automatically implemented.

\section{Payoffs}

In case the buyer opted out in this round in stage 4), both automatically and independently of the decisions [outcomes] in stage 3) and 5) receive 5 points for this round.

In case the seller decided to buy a solution in stage 4), then the payoffs for this round look as follows:

\section{Payoff for the seller:}

Revenue: + Price charged from the buyer ("price of solution I" or "price of solution II")

Costs: - Costs which arose by the chosen solution (20 or 40 Points)

- Taxes of 10 points, but only if at least one of the two participants (seller or buyer) voted against tax evasion [replaced by: only if it was determined that both a seller and his buyer evade the tax] [replaced by: only if the seller decided to pay the tax]

$=$ payoff for the seller in this round

\section{Payoff for the buyer:}

Revenue: $\quad+\mathbf{1 2 0}$ or $\mathbf{0}$ points (120 if his problem was solved, 0 if not)

Costs: - Price charged by the seller ("price of solution I" or "price of solution II")

- Taxes of 10 points, but only if at least one of the two participants (seller or buyer) voted against tax evasion [replaced by: only if it was determined that both a seller and his buyer evade the tax] [replaced by: only if the seller decided to pay the tax ]

= payoff for the buyer in this round 
At the end of the experiment you additionally will receive the payment of the government which depends on the amount of taxes and fees paid by the members of your group of eight.

At the beginning of the experiment you receive an initial endowment of 200 points. With this endowment you can cover losses that might occur during some rounds. Also, losses can be covered with gains from other rounds. In case you end up with an overall loss at the end of the experiment you are obliged to pay this amount to the experimenter. By participating in this experiment you agree to this term. Please mind that in this experiment losses can be avoided with certainty. At the end of the experiment your initial endowment, your payoffs from each round and the payment from the government will be summed up. This amount will be converted into cash money using the following exchange rate:

$$
\begin{gathered}
100 \text { points }=\mathbf{1} \text { euro } \\
\text { (i.e., } 1 \text { point }=1 \text { euro cent) }
\end{gathered}
$$

\section{Example (without considering the governmental payments):}

1) You are randomly matched with a participant of the other role.

2) Seller and buyer get to know the prices, which were determined by the computer for this round:

- "price of solution I" $=50$ points

- "price of solution II" = 70 points

3) The seller would like to evade the tax, and the buyer would like to pay the tax. [the last part of this sentence was deleted in treatment SELLER] Hence, the tax is paid by both in case a solution is sold. [replaced by: It is determined that you and your seller (buyer) pay the tax in case a solution is sold.]

4) The buyer continues this round and decides to buy a solution from the seller.

5) The seller learns that the buyer has problem I. He chooses solution I and charges the "price of solution II". Subsequently, he learns that the buyer decided to buy a solution in stage 4).

Seller's payoff: 50 ("price of solution I") - 20 (costs for solution I) -10 (taxes) $=20$ Buyer's payoff: 120 (problem solved) - 50 (“price of solution I") - 10 (taxes) $=60$ 